
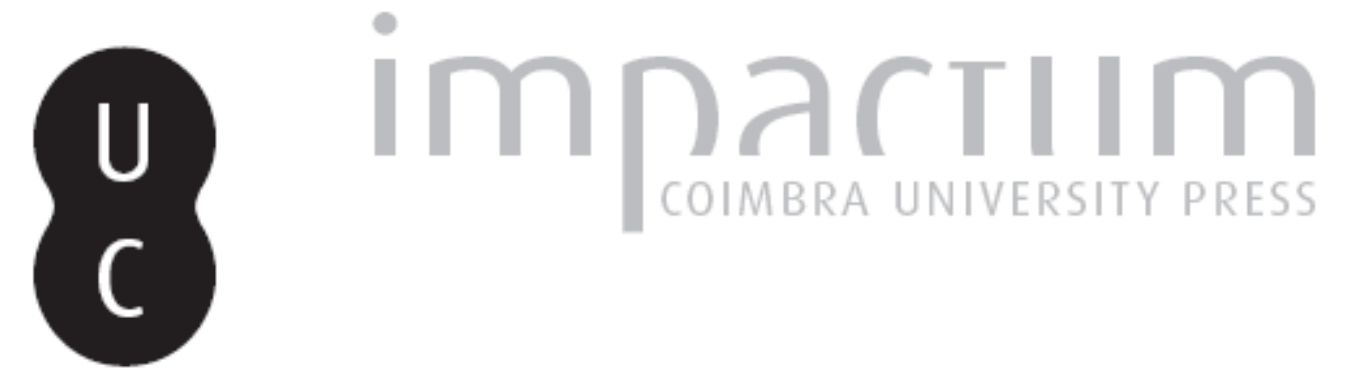

\title{
Algumas traduções italianas de três sonetos camonianos
}

\section{Autor(es): $\quad$ Sacco, Marcello}

Publicado por: Imprensa da Universidade de Coimbra

URL persistente:

URl:http://hdl.handle.net/10316.2/42642

DOI:

DOI:https://doi.org/10.14195/0870-8584_2_8

Accessed : $\quad$ 26-Apr-2023 12:58:22

A navegação consulta e descarregamento dos títulos inseridos nas Bibliotecas Digitais UC Digitalis, UC Pombalina e UC Impactum, pressupõem a aceitação plena e sem reservas dos Termos e Condições de Uso destas Bibliotecas Digitais, disponíveis em https://digitalis.uc.pt/pt-pt/termos.

Conforme exposto nos referidos Termos e Condições de Uso, o descarregamento de títulos de acesso restrito requer uma licença válida de autorização devendo o utilizador aceder ao(s) documento(s) a partir de um endereço de IP da instituição detentora da supramencionada licença.

Ao utilizador é apenas permitido o descarregamento para uso pessoal, pelo que o emprego do(s) título(s) descarregado(s) para outro fim, designadamente comercial, carece de autorização do respetivo autor ou editor da obra.

Na medida em que todas as obras da UC Digitalis se encontram protegidas pelo Código do Direito de Autor e Direitos Conexos e demais legislação aplicável, toda a cópia, parcial ou total, deste documento, nos casos em que é legalmente admitida, deverá conter ou fazer-se acompanhar por este aviso.

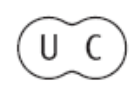




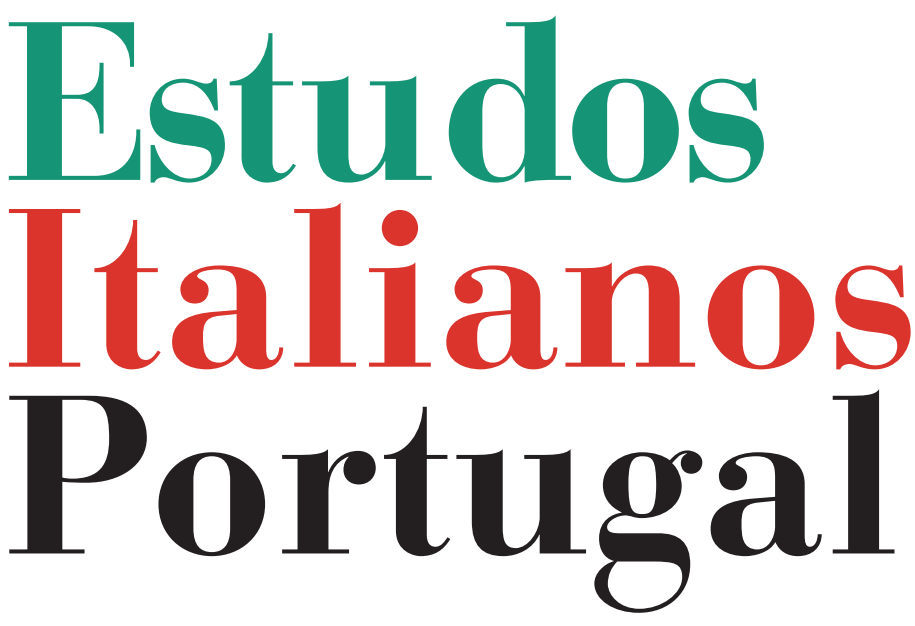

Instituto

Italiano

de Cultura

de Lisboa

Nova Série

$\mathbf{N}^{\mathbf{0}} 2$ 


\title{
ALGUMAS TRADUÇÕES ITALIANAS DE TRÊS SONETOS CAMONIANOS
}

\author{
Marcello Sacco ${ }^{\star}$
}

\section{Breve excurso bibliográfico ${ }^{1}$}

TALVEZ SEJA O GRANDE ÊXITO póstumo do seu poema maior a causa que explicaria a escassa fortuna de que Luís de Camões gozou em Itália como poeta lírico. O que, de facto,

* Marcello Sacco. Licenciado em Línguas e Literaturas Modernas pela Universidade de Lecce e Mestre em Estudos Portugueses pela Universidade Autónoma de Lisboa, com uma tese sobre Almeida Faria. Escreveu vários ensaios e artigos sobre artes e literatura. Como jornalista (com carteira profissional desde 1996), é autor de uma reportagem, juntamente com o fotógrafo Fausto Giaccone, sobre os trinta anos da Reforma Agrária em Portugal publicada na revista Diario (5-8-2005). Traduziu vários e prestigiados autores portugueses, entre os quais: Almeida Faria (Lusitânia, O Conquistador), Agustina Bessa-Luís (Fanny Owen), José Gil (Monstros). Em colaboração com G. Miraglia, organizou e traduziu a antologia L'Anima Navigante: racconti dal Portogallo (Besa, 2006).

1 Devo a maior parte das informações bibliográficas que refiro a G. Manuppella, Camoniana Itálica, Coimbra, 1972; ao catálogo com o mesmo título, Camoniana Itálica, da Biblioteca Nacional de Lisboa, 1980; aos prefácios de R. Averini a L. de Camões, I Lusiadi, Milão, Mursia, 1972 e L. de Camões, Rime, Lisboa, 1979 (número especial da revista Estudos Italianos em Portugal, que contém a antologia de líricas camonianas traduzidas pelo próprio Averini); e ainda aos mais recentes textos de R. Francavilla, "La letteratura portoghese in Italia oggi”, in R. Marnoto (org.), Caminhos da Italianística em Portugal, Instituto de Estudos Italianos, Faculdade de Letras, Coimbra; e de G. Miraglia, "Estudos Camonianos em Itália”, in Estudos Italianos em Portugal, nova série, n 1, 2006. Para uma ampla análise da recepção italiana do poeta português, cf. também H. de Almeida Chaves, O Mito de Camões em Itália, Lisboa, Colibri, 2001, livro 
reflecte os interesses e as apostas do próprio poeta, que afinal manifestava um certo desinteresse não pelo trabalho poético das Rimas, sempre cuidadoso, verdadeiro "campo de treino" para o poema maior, mas sim pela sua publicação, como os camonistas não deixam de nos relembrar:

[...] parece não se ter interessado muito pela edição das suas Rimas, que, no entanto, desde sempre cultivava e que o tornaram conhecido como excelente poeta mesmo antes da publicação d'Os Lusíadas em $1572^{2}$.

Ou terá sido, ainda, por causa da sua fama de poeta "petrarquista", que na pátria de Petrarca devia fatalmente despertar interesses mais brandos. Neste sentido, não é com certeza por acaso que um dos primeiros tradutores italianos notáveis do Camões "lírico", Tommaso Cannizzaro, não olha para ele como se de um émulo do poeta de Arezzo se tratasse, mas sim como o primeiro conceptista barroco, o poeta que fecha a fase mais autenticamente petrarquista da poesia europeia - superando, no género da poesia amorosa, o mestre "che al suo confronto ci par retorico e freddo" - e abre os caminhos por onde mais tarde enveredariam o cordovês Góngora e o napolitano Giambattista Marino ${ }^{3}$.

que, no entanto, não contém referências às traduções da lírica camoniana objecto do presente estudo. Quanto à bibliografia sobre teoria e prática da tradução, hoje em dia vastíssima, não é esta a sede idónea para tratá-la. Quero apenas declarar a minha dívida metodológica aos ensaios de G. Miraglia: "Le traduzioni italiane di Álvaro De Campos", in AA.VV., Del tradurre: 1, Roma, Bulzoni, 1992, pp. 161-176; e "Traduzioni portoghesi della Divina Commedia", in Polifonia, $\mathrm{n}^{\circ}$ 5, Lisboa, Colibri, 2002, pp. 135-152.

2 J. Mendes de Almeida, "No $4^{\circ}$ Centenário da $1^{\text {a }}$ Edição de 'Rimas' de Luís de Camões", in Estudos de História da Cultura Portuguesa, Lisboa, UAL, 1996, pp. 177-178.

3 T. Cannizzaro, "Introduzione”, a L. de Camões, Sonetti, Bari, Laterza, 1913, p. 14. Repare-se que Tommaso Cannizzaro (1838-1921) - figura original mas marginal de poeta e tradutor poliglota (escreveu poesia directamente em francês, 
Afinal, se a "fama do Épico arrastava a do Lírico", em Itália passava-se o mesmo com Torquato Tasso, cuja excelência como poeta lírico ficou quase em segundo plano perante a Gerusalemme liberata, obra de maior fôlego e maior ambição "ideológica". E esta é apenas uma das semelhanças possíveis entre os dois "grandi infelici" (como lhes chamou Giacomo Zanella, que traduziu um soneto do poeta, escolhendo infelizmente um título pseudocamoniano, Em huma lapa toda tenebrosa, incluído na edição do Visconde de Juromenha), que a tradição e os mitos - respectivamente camoniano e tassiano, tendo ambos a sua época áurea na Itália do século XIX - nunca deixaram de realçar.

Todavia, para além de tais mitos, permanece a certeza de que o próprio Tasso apreciava Os Lusíadas, chegando a afirmar, num soneto, que a pluma do "colto e buon Luigi" fora mais longe do que o próprio Vasco da Gama na sua viagem. Marino, por seu lado, fiel a uma certa ideia de literatura como colagem citacionista e plágio organizado (e autorizado), teria inserido trechos da obra-prima camoniana no seu Adone. O que, datando Adone de 1623, levantaria também a questão se terá existido ou não uma tradução italiana mais próxima da edição princeps d'Os Lusíadas - e, portanto, anterior à primeira tradução hoje conhecida, a de 1658, da autoria de Carlo Antonio Paggi - ou se o poeta napolitano teria lido o original português ou, em alternativa, as traduções espanholas disponíveis naquela altura.

traduziu a Divina Commedia em siciliano), amigo de Victor Hugo, Antero de Quental (que lhe dedicou um soneto) e Carolina Michaëlis de Vasconcellos (a quem dedicou a tradução dos sonetos camonianos) - publicou as primeiras traduções de 48 sonetos camonianos como apêndice ao estudo de Antonio Padula, Camoens petrarchista (1904). Cf. M. T. Morabito, "Tommaso Cannizzaro traduttore dal portoghese", in AA.VV., Scrittura e riscrittura. Traduzioni, refundiciones, parodie e plagi, Actas do Congress o da Associazione Ispanisti Italiani (Roma, 12-13 de Novembro de 1993), Bulzoni, Roma, 1995 [disponível em http://cvc.cervantes.es/literatura/aispi/pdf/06/06_145.pdf].

${ }^{4} \mathrm{~J}$. Mendes de Almeida, op. cit., p. 179. 
De qualquer forma, durante longos séculos a lírica de Camões encontra apenas tradutores ocasionais que nunca encetaram a tarefa de divulgar o poeta em Itália de forma sistemática. Veja-se o caso de Giulio Cesare Becelli, que num ensaio de 1732, tratando da poesia francesa e espanhola, dá também um exemplo da portuguesa com as traduções de Alma minha gentil e Sete anos de pastor; ou de Giovanni Ghinassi, que em 1860 publica a tradução do soneto a Pero Moniz numa antologia de "célebres escritores de várias nações" 5 . O mesmo se pode dizer do citado Zanella ou do português José António Viale, que insere dois sonetos camonianos no apêndice dum volume de traduções dantescas ${ }^{6}$. Merece ainda menção um livro cujo interesse, hoje, se adequa mais aos estudos de teoria da tradução ou à dialectologia italiana (e românica em geral) do que ao profundo e real conhecimento do poeta lusitano além fronteiras; refiro-me à publicação, organizada por Xavier da Cunha, que recolhia traduções em várias línguas das Endechas a Bárbara Escrava, apresentando versões em italiano, em siciliano, na tradução do próprio Cannizzaro, e noutros dialectos da península, com destaque para uma versão em napolitano, que traz mais uma assinatura famosa da poesia e até da canção de Nápoles: Salvatore Di Giacomo ${ }^{7}$. E repare-se agora nas datas e no atraso: com Ghinassi, Zanella, Viale e os outros já estamos em pleno século XIX. De facto, só em finais desse século é que deparamos com as primeiras tentativas orgânicas de constituição de um corpus da lírica camoniana em italiano. A primeira antologia, apesar de excessivamente "magra", é de Prospero Peragallo ${ }^{8}$, tradutor menos ocasional que os seus

5 Cf. G. Manuppella, op. cit.

${ }^{6}$ J. A. Viale, Tentativas Dantescas, Coimbra, 1883.

7 Cf. X. da Cunha, Pretidão de Amor, Endechas de Camões a Bárbara Escrava seguidas da respectiva tradução em várias línguas, Lisboa, Imprensa Nacional, 1893.

${ }^{8}$ Reitor da igreja italiana de Lisboa (Nossa Senhora do Loreto), autor de estudos históricos sobre os Descobrimentos (em particular Cristóvão Colombo) 
antecessores e não desprovido de uma certa dose de talento e bom gosto, apesar das fraquezas que não deixaremos de apontar. Publicou a sua antologia numa edição elegante, de tiragem limitada, limitando também a sua selecção a poucos sonetos. Sintoma desde já evidente de que o interesse pela produção lírica do poeta d'Os Lusíadas, para os compatriotas de Jacopo da Lentini, parece destinado a cingir-se ao soneto.

De facto, a mais notável e ponderosa publicação camoniana em Itália - evento editorial tão importante que Riccardo Averini o define como fundamental para o início da moderna camonística italiana - será precisamente o corpus completo dos sonetos, traduzidos pelo já mencionado Tommaso Cannizzaro e publicados em 1913 pela prestigiada editora Laterza ${ }^{9}$. Infelizmente a de 1913 correu (e ainda corre?) o risco de marcar uma data ao mesmo tempo inicial e final, pelo menos no que respeita não à tradução do Camões épico, mas do Camões lírico. As compilações que se seguiram continuaram a ser muito reduzidas, sempre localizadas em macrotextos mais abrangentes (sobretudo a revista Estudos Italiano em Portugal) e focando muito pouco a figura do poeta para que mereçam o nome de antologias ${ }^{10}$. Será preciso es-

e sobre a comunidade italiana em Portugal; como tradutor, Prospero Peragallo (1823-1916), para além das experiências camonianas, deixou apenas alguns poemas de Antero de Quental na antologia de A. Padula, I nuovi poeti portoghesi (1896) e um mélange de "poesie sivigliane" publicado em Génova em 1898. A edição aqui consultada é: L. de Camões, Sonetos escolhidos traduzidos em sonetos italianos com variantes por Prospero Peragallo, Lisboa, 1885. A este seguiram-se os volumes: Poesias de Luís de Camões e outros vertidas a italiano por Prospero Peragallo, Lisboa, 1890; Due episodi del poema "I Lusiadi" ed altre poesie straniere, Génova, 1904, cujo amadorismo é patente na tiragem limitada (o livro de 1904 foi produzido em 80 exemplares por ocasião do casamento de um sobrinho) e em que se destacam as numerosas variantes de tradução do soneto Alma minha gentil.

9 Op. cit.

10 Cf. G. C. Becelli, Poesie portoghesi, Roma, Società Editrice Dante Alighieri, 1899; as traduções de R. Barchiesi, in Estudos Italianos em Portugal n ${ }^{\circ} 25,1965$; e as de E. Di Poppa Vòlture, in Estudos Italianos em Portugal, n 29, 1967. 
perar por Riccardo Averini ${ }^{11}$ e o seu número especial de Estudos Italianos em Portugal de 1979, decorrido já quase um século desde a publicação do livrinho de Peragallo, para ter uma verdadeira antologia que dê conta da variedade de estilos, formas e metros da produção lírica de Luís de Camões.

Por esta razão, a nossa escolha para este estudo, que não dispensará referências pontuais a outras traduções, recaiu principalmente sobre Peragallo, Cannizzaro e Averini, únicos tradutores de fôlego cujo trabalho nos permite análises comparadas com base nos mesmos textos, nomeadamente três sonetos entre os mais conhecidos por quem conhece Camões.

\section{O SONETO}

Estranha magia, a das formas fechadas. Serão as mais dificeis de traduzir ou antes as mais fáceis? O tradutor, como o próprio poeta, às vezes necessita de regras estritas que o condicionem e, ao mesmo tempo, o guiem nessa sua tentativa louca de seguir o rasto de um autor afastando-se dele e dirigindo-se para outro universo simbólico, uma língua estrangeira. Irónico como de costume, foi o vanguardista Álvaro de Campos quem descreveu bem, após tanto verso livre e tanta experimentação literária, essa sensação confortável, apesar das estritas regras de composição, que o poeta pode chegar a sentir perante uma forma tão rígida e rigorosa como o soneto:

11 Director durante doze anos do Instituto Italiano de Cultura de Lisboa, Riccardo Averini (1915-1980), para além das suas traduções camonianas, é conhecido também pelos seus ensaios sobre arte portuguesa e sobre os artistas italianos que trabalharam em Portugal, tendo participado também no lançamento dos estudos especializados de História de Arte na Universidade Nova de Lisboa. Cf. J. A. França, "Em Memória do Professor Riccardo Averini", in Estudos Italianos em Portugal, n 43-44, 1980-81, pp. 15-20. 
Graças a Deus, ainda sei que ha Quatorze linhas a cumprir eguaes Para a gente saber onde é que está... ${ }^{12}$

Quanto às suas características histórico-formais, diz o poeta mexicano Octavio Paz que esta forma poética, tão breve e perfeita, conservou durante séculos, desde a sua aparição, um dualismo neoplatónico e uma sintaxe rigorosa entre as suas partes:

Ahora bien, desde su introducción en Francia, y lo mismo sucedió en España y Portugal, el soneto adoptó, en general, la división sintáctica cuatripartita que los poetas italianos, sobre todo Petrarca, le habían dado: cuatro frases, una en cada uno de los cuartetos y tercetos ${ }^{13}$.

Uma forma de "pensar poeticamente" cujo rigor lógico, sem chocar com as exigências da arte e as licenças da fantasia, nos remete para o âmbito da mais antiga filosofia formal:

La mayoría de los sonetos están compuestos, tanto en francés como en italiano, español y portugués, por cuatro frases: el primer cuarteto es una exposición, el segundo su negación o alteración, el primer terceto es la crisis y el último el desenlace. El soneto es una proposición o, mejor dicho, cuatro proposiciones encadenadas por una lógica no menos rigurosa que la que ata a los miembros de un silogismo ${ }^{14}$.

Por isso, confirmam os estudiosos das formas métricas italianas, "Poté così prestarsi all'invenzione lirica e alla pole-

12 Álvaro de Campos, Livro de Versos, (ed. T. R. Lopes) Lisboa, Estampa, 1993, p. 349.

13 O. Paz, Traducción: literatura y literalidad, Barcelona, Tusquets, 1971, p. 50.

14 Ibidem, pp. 50-51. 
mica letteraria"15. Tal como desejava o pai da dialéctica implícita na "forma sonata", o Domenico Scarlatti de José Saramago que, em Memorial do Convento, dizia: "Quisera eu, senhor padre Bartolomeu de Gusmão, que a minha música fosse um dia capaz de expor, contrapor e concluir como fazem sermão e discurso"16, também a lógica do soneto é uma tentativa de fusão de âmbitos distantes, uma lógica racional e ao mesmo tempo musical; uma forma ditada tanto pela consequencialidade do raciocínio (trata-se, às vezes, de autênticas teses ou aforismos) como pelo encadeamento das rimas. Regras a que o tradutor não pode fugir, se não quiser atraiçoar a letra e o espírito da obra que se comprometeu a transladar, como mercadoria valiosa, de um país (de uma língua, de um mundo) para outro.

Ora, o estudo das traduções italianas da lírica de Camões, precisamente por causa do atraso, já referido, na descoberta e devida valorização das suas Rimas, não nos proporciona um amplo panorama de estilos e de "filosofias da tradução" que poderiam ter surgido ao longo dos séculos, se ao longo dos séculos poetas e tradutores se tivessem dedicado às rimas camonianas. O que falta é precisamente uma variedade de tipos e de estilos de tradução que possam permitir um amplo estudo comparado, por forma a traçar uma espécie de "história das ideias" aplicadas às traduções reais. No caso dos poucos sonetos que a seguir vamos examinar, nota-se uma evolução rápida e instável do gosto e da língua, avanços e recuos concentrados em poucas décadas: desde um estádio ainda tardo-romântico, em finais do século XIX, a uma abordagem mais moderna no que concerne tanto à língua "de chegada" como à própria atitude do tradutor para com

15 M. Pazzaglia, Manuale di metrica italiana, Florença, Sansoni, 1990, p. 137.

Sobre a "forma soneto" em Camões e suas relações com a cultura italiana e o resto da cultura ibérica, cf. ainda o fundamental: J. de Sena, Os Sonetos de Camões e o Soneto Quinhentista Peninsular, Lisboa, Edições 70, 1980.

16 J. Saramago, Memorial do Convento, Lisboa, Caminho, 1982, p. 158. 
a obra original. É a famosa questão da "fidelidade", que sempre se levanta a propósito de traduções de clássicos, e não só, mas que é preciso manusear com a flexibilidade necessária para um bom trabalho crítico sobre esse trabalho literário específico que é a tradução.

3. Os SONETOS ${ }^{17}$ :

3.1 Sete anos de pastor Jacob Servia

Sete anos de pastor Jacob servia

Labão, pai de Raquel, serrana bela; mas não servia ao pai, servia a ela, e a ela só por prémio pretendia.

Os dias, na esperança de um só dia, passava, contentando-se com vê-la; porém o pai, usando de cautela em lugar de Raquel lhe dava Lia.

Vendo o triste pastor que com enganos

lhe fora assi negada a sua pastora, como se a não tivera merecida;

começa de servir outros sete anos, dizendo: - Mais servira, se não fora para tão longo amor tão curta a vida.

Este famoso soneto molda o tema bastante vulgar do “escravo de Amor" a partir dum episódio bíblico (Génesis 29, 16-30), aqui desenvolvido de forma extraordinariamente original e imaginativa. A ideia - tal como nos outros dois sonetos, claramente inspirados, como veremos, em fontes

17 A edição dos sonetos utilizada é: L. de Camões, Rimas, texto estabelecido e prefaciado por Á. J. da Costa Pimpão, Almedina, Coimbra, 1994; mas também foi consultada, quando necessário, a edição crítica de Leodegário A. de Azevedo Filho (cf. infra, n. 23). 
poéticas italianas, especialmente Petrarca - tem antecedentes significativos para uma crítica que queira detectar as origens e levar a cabo um estudo contrastivo. Mas aqui a iniciativa e a singularidade de Camões são ainda maiores que em outras circunstâncias. Já Carolina Michaëlis de Vasconcelos, realçando a originalidade absoluta com que Camões desenvolve o tema, cita os Trionfi de Petrarca e traça uma breve história do episódio bíblico na poesia ibérica $^{18}$. Falta acrescentar, quanto à poesia italiana, outras possíveis mas não incontornáveis fontes literárias, ou seja, alguns versos de Giovanni Boccaccio e de Luigi Pulci, que não necessariamente terão tido influência directa no poeta português. O primeiro, nas Rimas, relembra como Amor faz com que sujeitemos a nossa alma a Lia, aqui metáfora um tanto ou quanto ingrata do sacrificio, por causa de Raquel, sinónimo do verdadeiro amor (Amor, che con sua forza e virtù regna):

Unde sovente per Rachele a Lia fa star suggetta l'anima servendo con dolce voglia e con la mente pia.

Enquanto o segundo, no Cantare 16 do seu poema Morgante, aborda o episódio com um certo gosto pelo paradoxo e pela hipérbole, retratando o oposto ao amor fiel, pois o Jacob de Pulci deixaria de servir por Raquel se visse a beleza de Antea, mulher amada por Rinaldo:

Né tanto tempo Giacobbe fedele, ché, veggendo costei, come discreto, serviva per Antea, non per Rachele

18 C. Michaëlis de Vasconcelos, "Sete Anos de Pastor Jacob Servia", in Círculo Camoniano, Porto, 1889, p. 149-159. 
Referências breves e fugidias à figura de Jacob que, todavia, pouco têm a ver com Camões, único em dar à sua personagem a plenitude da imagem poética e toda a força metafórica da constância no amor.

Vejamos agora as traduções italianas.

\section{PERAGALLO}

Jacob sett'anni qual pastor servia

Laban padre a Rachel, vaga donzella;

Ma non al padre, sì servia alla bella,

Che sola in premio a sue fatiche ambia.

D'un sol dì nella speme egli venìa

Passando i giorni, pago in veder quella:

Usando però il padre un'arte fella,

In luogo di Rachel, gli diede Lia.

Visto il mesto Pastor che con inganni

La pastorella sua gli era negata,

Quasi indegno foss'ei di averne il core,

Si ridusse a servir altri sett'anni,

Con dir: più servirei, se più durata

La vita avesse per sì lungo amore.

\section{CANNIZZARO ${ }^{19}$}

Giacobbe sette lunghi anni serviva

Lában, padre a Rachel l'alpigianella, par non lui serviva ma la giovin bella e lei soltanto per suo premio ambiva.

In un sol dì sperando, i dì seguiva pago sol di mirar la pastorella, ma cauto il padre de la verginella, in cambio di Rachel Lia gli largiva.

Il misero pastor, visti gl'inganni, che gli rapian le belle guance rosse qual se mertato ei non ne avesse il fiore,

19 A edição de Cannizzaro não apresenta a subdivisão em quadras e tercetos. 
ricominciò a servire altri sette anni, più servirei, dicendo, se non fosse così breve la vita a tanto amore.

\section{AVERINI}

Per sette anni Giacobbe da pastore

Servì Labano, padre di Rachele.

Non del padre, di lei schiavo fedele

$\mathrm{fu}$, per averla in premio del suo amore.

Attendendo quel giorno, tutte le ore le stava appresso e l'ammirava ne le sue grazie. Prese allor le sue cautele e, in cambio, Lia gli diede il genitore.

Vedendo che negata con gl'inganni, come se meritata non l'avesse, gli era la pastorella preferita, egli a servir si diede altri sett'anni, dicendo:

«Più farei, se confacesse:

ma a così lungo amor corta è la vita».

Como é fácil de imaginar, o incipit é importantíssimo para a tradução estabelecer desde o princípio o "naipe" de rimas, o metro, o ritmo e ao mesmo tempo garantir a maior proximidade semântica possível com o original. Tanto Peragallo como Cannizzaro conseguem, logo na primeira quadra, conservar as mesmas rimas que em português; idênticas, no caso de Peragallo, graças a um arcaísmo ainda bastante frequente na poesia italiana dessa época: o imperfeito "siciliano" servia/ambia, que Cannizzaro, por sua vez, não hesita justamente em transformar no mais comum serviva/ambiva. Outra rebuscada invenção de Peragallo, de um certo gosto passadista que poderá levantar algum cepticismo, mas no fundo coerente com o seu estilo, é a tradução de "serrana bela" por "vaga donzella", em que não 
só o substantivo "donzella", mas também o adjectivo "vaga" enquanto sinónimo de "bela" nos remetem, evidentemente, para o vocabulário leopardiano. Como voltaremos a apontar nas conclusões, o estilo deste tradutor será geralmente coerente, mas a escolha lexical, neste caso concreto, não nos devolve o estilo de Camões, antes parece encarnar a escrita de um poeta italiano menor de finais do século XIX. No entanto, a escolha de Cannizzaro tão-pouco me parece preferível. Se, do ponto de vista semântico, "donzella" não é o mesmo que "serrana", pois perde-se a referência à serra e aos montes, Cannizzaro opta por um bastante discutível "alpigianella", surpreendente palavra que é, sim, sinónimo de serrana ou montanhesa, mas com esse morfema que nos relembra inevitavelmente os Alpes, localização geográfica pouco idónea para um soneto de ambientação bíblica. É de notar que ambos são obrigados a procurar soluções complexas para a palavra "serrana", de ambígua aplicação na língua italiana, pois não consta dos dicionários, apesar de existir a palavra "serra", mas invulgar na acepção, entre outras, de "catena montuosa allungata e senza forti avvallamenti". Roberto Barchiesi, que traduziu o soneto em 1965, utiliza sem inibições o neologismo "serrana" numa versão que, por outro lado, não desdenha de arcaísmos hiper-literários. A ideia com que se fica é que uma solução menos atrevida, tanto em sentido "passadista" como em sentido "futurista" (o neologismo), teria sido possível, não sendo "serrana", ao que tudo indica, uma palavra-chave do soneto.

Bem diferente é a dificuldade representada pelos nomes próprios bíblicos que, no caso de Raquel (it.: Rachele) e de Labão (it.: Labano), pode ser resolvida com a apócope da vogal final, mas no caso de Jacob (it.: Giacobbe) leva, por exemplo, Peragallo a manter o nome em português. Nesse caso poderia ter optado por Iacob, forma rara mas documentada na poesia antiga, já a partir de Dante (aliás, não é de 
excluir que Peragallo pensasse na homografia da palavra, pronunciada diferentemente pelo leitor italiano, sendo o som do 'j' vocálico e equivalente a um 'i’). Outra possibilidade teria sido "Giacob", forma ainda mais rara, mas utilizada, na sua tradução de 1732, por Giulio Cesare Becelli (versão que Peragallo, como veremos adiante, provavelmente conhecia). Seja ela qual for, a opção linguística do tradutor teria sido mais compreensível se tivesse respeitado a mesma ordem de palavras do original, coisa perfeitamente possível, uma vez que se utilizava o demasiado exótico "Jacob" em lugar de Giacobbe (ex.: "Sett'anni qual pastor Jacob/Iacob servìa"). Contudo, nem a tradução de Peragallo, nem as outras aqui examinadas seguem a ordem camoniana, perdendo-se assim o pé métrico e a própria força retórica - importantíssima num soneto sobre o contraste entre o passar do tempo e o perdurar do amor - daquele complemento temporal inicial: "Sete anos". Enfim, estamos perante um daqueles casos em que a necessidade de forçar o texto nem sempre encontra uma justificação coerente na totalidade do trabalho realizado.

É precisamente a partir da opção pelos nomes italianos absolutamente inalterados, ou seja, sem apócope, que se define a quadra, o andamento geral e a escolha das rimas da mais moderna tradução de Riccardo Averini. Quanto à sua "modernidade", note-se que a tradução de Barchiesi, cerca de quinze anos mais antiga, é um trabalho insatisfatório precisamente porque, como já se disse, é fruto de uma indecisão prejudicial entre a concepção moderna, que chega a recusar as rimas, e desnecessárias pitadas de arcaísmos como o imperfeito "siciliano" em "ía”, que já na época de Peragallo devia parecer antiquado. Nada disso existe na mais adequada e conseguida tradução de Averini, que fecha inclusive o segundo verso com o nome "Rachele", ditando assim as rimas desta e da quadra sequente (um pouco mais infeliz, como veremos) e obrigando o tradutor a introduzir termos 
inexistentes no original, mas que, pelo paradoxo a que os tradutores estão habituados, parecem muito mais naturais e "camonianos" do que algumas opções, demasiado "italianas", que acabamos de ver nos outros. É o caso de "schiavo fedele" (escravo fiel), que com eficácia resolve e traduz, ficando no mesmo campo semântico, a iteração do verbo "servir" que se encontra no original. A rima em "èle", todavia, obriga Averini a fechar o sexto verso (logo na segunda quadra) com uma preposição articulada que aqui encontramos estranhamente desarticulada, ou seja, dividida, a fim de evitar o "l" geminado ("ne le" em lugar de "nelle"). Desta forma a rima fica, de facto, perfeitamente idêntica, mas a custa de o tradutor se servir dum arcaísmo ortográfico, hoje absolutamente desusado, que choca com o contexto linguístico do resto da tradução, acabando paradoxalmente por se parecer mais com o contraponto irónico de um poeta contemporâneo (digno, por exemplo, de Alberto Arbasino ou Giovanni Giudici). Da mesma forma a rima em "óre", que vinha de "pastore", a fechar o primeiro verso, faz com que se acrescente "ore" (horas), perdendo-se a iteração da palavra "dia”, que em Camões exprime magnificamente a passagem monótona do tempo em contraste com a persistência do amante. Palavra que Cannizzaro consegue conservar num verso e numa quadra perfeitamente conseguidos, enquanto Peragallo, enlevado pela tendência arcaizante, se perde numa linguagem excessivamente conservadora que já no seu tempo devia soar "a alfarrabista", como demonstram os seus "speme" ("esperança", célebre latinismo do repertório áulico italiano) e arte "fella", adjectivação rara, provavelmente decalcada do antecedente de Becelli ("... avara astuzia e fella"). Efeitos de antiguidade, típicos de uma certa tendência conservadora da língua poética italiana, alheios ao próprio texto camoniano, aqui extraordinariamente simples e eficaz. 


\subsection{Alma minha gentil, QUe te Partiste}

Alma minha gentil que te partiste tão cedo desta vida descontente, repousa lá no Céu eternamente, e viva eu cá na terra sempre triste.

Se lá no assento etéreo, onde subiste, memória desta vida se consente, não te esqueças daquele amor ardente que já nos olhos meus tão puro viste.

E se vires que pode merecer-te algua cousa a dor que me ficou da mágoa, sem remédio, de perder-te, roga a Deus, que teus anos encurtou, que tão cedo de cá me leve a ver-te, quão cedo de meus olhos te levou.

Cantando o tema da derradeira despedida e da tão desejada conjunção dos amantes na morte, este soneto é eminentemente petrarquista. O tema encontra-se em Anima bella, da quel nodo sciolta, cujas afinidades e divergências já foram devidamente apontadas pela crítica ${ }^{20}$. Todavia, o primeiro verso é tirado de outro soneto de Petrarca, Questa anima gentil che si diparte, parecendo, aliás, uma autêntica tradução livre que, porém, deixa de lado a complicada astronomia dos restantes versos em que o poeta italiano, adulterando o ar lutuoso do incipit, passa a dedicar-se a comparações um tanto ou quanto cerebrais entre a mulher que acaba de morrer e as estrelas junto das quais irá tomar assento nos céus. Nem sempre Cannizzaro tem razão, mas este é um daqueles casos em que nos ocorrem as suas palavras acerca da presumível frieza do poeta italiano quando comparado

${ }^{20}$ Cf. A. Pellizzari, "Un sonetto di F. Petrarca e uno di L. de Camões", in Portogallo e Italia nel sec. XVI, Nápoles, 1914. 
com o português, que compõe as suas obras juntando uma intensa leitura das fontes a um total à-vontade criativo. Como nos relembra Rita Marnoto no seu incontornável ensaio sobre o petrarquismo português:

Para o homem do Renascimento, o valor de uma obra literária é indissociável da sua capacidade de modelizar outras obras já escritas, de reconhecido valor ${ }^{21}$.

No entanto, apesar de Petrarca ser um nume tutelar para este trabalho de modelização:

[...] não deverá ser descurado o facto de a reprodução desses passos, na sua língua original, ao implicar uma inserção num novo contexto, nem sempre levar à fiel preservação do seu sentido primitivo ${ }^{22}$.

E, de facto, a engenharia poética de Camões não conhece limites: aproveitando livremente os temas que o repertório italiano lhe proporcionava, ele vai buscar a outro soneto de Petrarca, Donna, che lieta col principio nostro, tanto o último verso ("prega ch'i' venga tosto a star con voi" /"que tão cedo de cá me leve a ver-te") como a ideia de que o amor humano se reflecte no amor divino, sendo uma imagem especular do outro. Mas a intuição mais poética pertence ainda a Luís de

21 R. Marnoto, O Petrarquismo Português do Renascimento e do Maneirismo, Universidade de Coimbra, 1997, p. 331.

22 Op. cit., p. 343. E ainda: "Mais frequente é a imitação directa de temas e estilemas petrarquistas a partir da concatenação e do cerzimento de elementos de proveniência textual diversa" (ibidem). Sobre o predomínio da tradução entendida como metáfrase, paráfrase e imitação e a paralela escassez de traduções propriamente ditas do corpus petrarquesco no Portugal de Quinhentos, cf. também: R. Marnoto, “'Spero trovar pietà, nonché perdono'. Tradução e imitação no lirismo português do século XVI", in Critica del testo, VI/2, 2003, pp. 837-851. 
Camões e, quando muito, parece indirectamente mais devedora à leitura do outro grande poeta italiano do Além e das almas penadas. Refiro-me àquela hesitação - espécie de subtil nuance que é ao mesmo tempo psicológica e teológica, como só Dante conseguia pincelar - acerca das recordações e sentimentos terrenos que as almas dos finados poderão ter ou não ter no Céu ("Se lá no assento etéreo..." v. 5-6).

Vejamos as traduções:

\section{PERAGALLO}

Gentil anima mia, che ten partisti

Dal mondo così presto dispiacente,

Riposa là nel cielo eternamente,

E viva io quaggiù sempre giorni tristi.

Se nell'eterea sede, ove salisti,

Pensier di questa vita si consente,

Non ti scordar di quell'amore ardente

Che già negli occhi miei puro scopristi.

E se di merto vedi che m'adorno

Nel duol onde ferito il cor restò

Per la partenza tua senza ritorno,

Prega Dio, che i tuoi verdi anni abbreviò,

Che sì presto mi tragga a te d'intorno,

Come presto a' miei occhi ti rubò.

\section{CANNIZZARO}

Soave anima mia che ti partisti da la misera terra impaziente, su nel cielo riposa eternamente, sol'io qui resti in queste lande tristi!

Se ne l'eterna sede ove salisti ricordarti del mondo si consente, non obliar quell'amor puro, ardente che un giorno tu negli occhi miei scopristi. 
E se vedrai che meriti alcun fiore l'ambascia senza balsamo di averti perduta, e che mi dà tanto dolore,

prega Iddio, che sì fresca a sé ti accolse, che mi richiami al ciel per rivederti sì râtto come râtto a me ti tolse.

\section{AVERINI}

Anima mia gentile che partisti presto ed insoddisfatta della vita, or dall'eterna quiete sii blandita e giorni in terra io viva sempre tristi.

Se nell'etereo seggio a cui salisti memoria di quaggiù non ti è impedita, non può in essa la fiamma esser svanita, ch'arse negli occhi che di te nutristi.

E se valga, a sollievo del mio stato, pietà, visto il dolore acerbo ch'io provo per essere di te privato senza speranza di rimedio, Dio prega che ci riunisca e che abbreviato, come avvenne per te, sia il viver mio.

As traduções deparam-se com um primeiro verso que Peragallo e Cannizzaro, por um lado, e Averini, por outro, resolvem de forma diferente, dir-se-ia mesmo oposta. Os dois primeiros conservam a forma reflexiva do verbo "partire" e Peragallo, não respeitando a disposição das palavras do original, antecipa o adjectivo "gentil", que Cannizzaro transforma inútil e injustificadamente em "soave". Averini consegue mais uma vez ser não apenas o mais moderno (o que seria de esperar), como também o mais camoniano, sendo a disposição das palavras no seu soneto a mesma que em Camões, com a vantagem, entre outras, de evitar uma desnecessária - se não mesmo obsoleta - forma reflexiva ("ten 
partisti”). Todavia, também Peragallo conserva uma louvável adesão ao texto original. Notável o seu "dispiacente", que nos remete para o campo semântico do desagrado e do descontentamento, enquanto as outras soluções são claramente mais insatisfatórias: em Cannizzaro esse descontentamento transforma-se numa estranha impaciência ("impaziente"), que tanto pode ser fastio como autêntica pressa em morrer. Por outro lado, a boa tradução "insoddisfatta della vita" obriga Averini a transformar o repouso eterno numa "lisonja" eterna ("sii blandita"). Mas, apesar dos defeitos lexicais, quer Averini quer Cannizzaro obtêm resultados legíveis e interessantes no que diz respeito à conservação da figura rítmica. Neste aspecto, a grave falha é de Peragallo, que fecha a quadra com um verso que cabe no decassílabo só a custo de uma sinalefa tão improvável ("viv'io") que o próprio autor evita assinalá-la ortograficamente e que cria, ainda, diferenças demasiado grandes entre acentos tónicos das palavras e acentos rítmicos do verso (sístole em "quaggiù"), imbricando assim a leitura numa escansão defeituosa. As coisas mudam na segunda quadra, sendo a de Peragallo tão perfeita que parece conter potencialmente todas as soluções dos tradutores que se seguiram. Conserva-se o ritmo, a unidade métrica, as rimas e uma feliz escolha lexical que os outros repetem, com a excepção de Cannizzaro quando traduz o português "etéreo" pelo adjectivo "eterno" (aqui no feminino: "eterna”); variação absolutamente inútil, visto existir em italiano o mesmo adjectivo. Decerto Cannizzaro não se baseia numa lição textual diferente, pois deste soneto Faria e Sousa acolheu a edição de 1598 e "daí em diante, quase sempre, o texto [...] foi reproduzido até chegar aos nossos dias"23. Será o erro devido a gralha tipográfica, leitura desatenta ou procura de soluções excessivamente rebuscadas?

23 Leodegário A. de Azevedo Filho, Lírica de Camões; Sonetos, vol. 2, tomo 1, p. 106, Lisboa, Imprensa Nacional, 1987. 
Por muito estranho que pareça, acontece a muitos tradutores, talvez por razões psicológicas subtis, evitar a solução mais simples mesmo quando é evidente tratar-se da mais idónea, isto é, quando as duas línguas oferecem palavras iguais ou muito parecidas para expressar o mesmo conceito numa rara e proveitosa proximidade de significante e significado (a identidade não existe, até dentro da mesma língua; é sabido que, para o linguista, a sinonímia perfeita é uma quimera).

Muito eficaz, em Peragallo, é também aquele "non ti scordar" (não te esqueças) do verso 7 , simples e bonito como simples e bonita é a dicção do próprio Camões, ao contrário das soluções mais rebuscadas escolhidas pelos outros autores, tendo Cannizzaro optado por um desusado "obliar" e Averini - sempre homogéneo estilística e linguisticamente, mas deixando escapar aqui toda a força do imperativo "não te esqueças" - pela metáfora da chama não apagada, que no original não existe mas que se justifica com a necessidade de respeitar a rima.

(Note-se ainda, de passagem, que a quadra de Peragallo é tão eficaz que até um tradutor tão recente como Enzio di Poppa Vòlture não pôde fazer mais do que reproduzi-la quase tal e qual; falhando, aliás, sempre que procura afastarse dela, por exemplo quando repete a escolha de "eterna", já vista em Cannizzaro).

É, porém, no remate dos dois tercetos que o discurso de Camões se torna mais difícil de traduzir, pela lógica ao mesmo tempo rigorosa e paradoxal de quem pede a morte como prémio merecido pelo seu amor. No primeiro terceto, todos traduzem as palavras-chave ligadas aos conceitos de "merecer" (o castigo/prémio da morte) e de "dor". Notável, em Averini, o envolvimento de Deus ("Dio") na rima com "eu" ("io") e "meu" ("mio") e os encavalgamentos que fraccionam o fluir dos dois tercetos. Averini é também o único que, afastando-se, como sempre, mais que os outros da sintaxe do original, evita a reprodução das palavras "dor" 
e "mágoa", de difícil tradução e diferenciação em italiano pela grande proximidade semântica que há entre elas. Peragallo resolve com "duol” (dor) e com a introdução da figura do coração ferido, inexistente em Camões, enquanto a solução mais fraca parece ser a de Cannizzaro que, além de alterar ligeiramente o esquema métrico (CDC-DCD no original, CDC-EDE na tradução), não revela uma escolha lexical muito feliz: o hiper-literário "Ambascia" por "dor", merecer uma flor ( ote fiore") em vez de "alguma coisa" ou "balsamo" por "remédio" são exemplos de uma língua demasiado artificiosa. Camões era um poeta pré-barroco que, com certeza, amava os conceptismos e algum tour de force sintáctico, mas sempre com base numa língua sólida e robusta, que às vezes nos deixa espantados pela capacidade de nominação directa, e despojada de ouropéis verbais que é absurdo reproduzir e multiplicar nas traduções.

\subsection{TANTo De MeU estado ME ACHO incerto}

Tanto de meu estado me acho incerto, que em vivo ardor tremendo estou de frio; sem causa, juntamente choro e rio, o mundo todo abarco e nada aperto.

É tudo quanto sinto, um desconcerto; da alma um fogo me sai, da vista um rio; agora espero, agora desconfio, agora desvario, agora acerto.

Estando em terra, chego ao Céu voando, nu'hora acho mil anos, e é de jeito que em mil anos não posso achar u'hora.

Se me pergunta alguém porque assi ando, respondo que não sei; porém suspeito que só porque vos vi, minha senhora. 
A composição é inspirada no "sonetto per eccellenza del petrarchismo europeo"24: Pace non trovo, et non ò da far guerra, sendo a de Camões uma variante originalíssima e ao mesmo tempo "fiel", como quando insere versos que são brilhantes traduções, jóias petrarquistas num anel absolutamente camoniano ("Et nulla stringo, et tutto 'l mondo abbraccio"/ "O mundo todo abarco e nada aperto"; "Et volo sopra "l cielo et giaccio in terra"/"Estando em terra, chego ao Céu voando"), exemplos de contaminação cultural e liberdade absoluta ${ }^{25}$.

Pietro Bembo (Lasso me, ch'ad un tempo e taccio e grido) poderá ter sido outra fonte para variações e figurações possíveis sobre o tema originário que a psicologia moderna classificaria de fragmentação do ego e que, para o poeta clássico, permanece um bom "cabide" em que pendurar um deslumbrante repertório de antíteses: "Pascomi di dolor, piangendo rido" (Petrarca)/"De' miei danni egualmente piango e rido" (Bembo)/ "Sem causa, juntamente choro e rio" (Camões).

As traduções:

\section{PERAGALLO}

Del mio stato così mi trovo incerto,

Che, vivamente ardendo, io son di ghiaccio:

E rido e piango senza alcun fin certo;

E nulla stringo, e tutto il mondo abbraccio.

Quanto sento entro me, tutto è sconcerto:

Dagli occhi un fiume sgorga, e in fuoco io giaccio;

Or spero, or a fiducia sono aperto;

Or seguo il vero, or nell'error m'impaccio.

E volo sopra il ciel, pur stando in terra:

Parmi un'ora mill'anni, e di diletto

In mill'anni trovar non posso un'ora.

24 C. Guerrieri, La lirica del Camões, Génova, 1939, p. 63.

${ }_{25}$ Para uma análise comparada deste soneto e da sua fonte petrarquesca cf. também R. Marnoto, O Petrarquismo Português..., pp. 353 e sgs. 
Se alcun mi chiede: perché in me tal guerra? Rispondo, nol saper: però sospetto Che sol perché vi vidi, o mia signora.

\section{CANNIZZARO}

Son del mio stato di tal guisa incerto che tremiti ho di freddo in vivo ardore e riso e pianto,onde non so, vien fuore e abbracciar tutto e stringer nulla avverto.

L'anima tutta è in iscompiglio aperto, dagli occhi un fiume, un fuoco esce dal cuore, ora spero, ora dispero con dolore, vaneggio qui, là indovinar son certo.

Saldo alla terra, al ciel m'innalzo a volo, parmi un'ora mill'anni e di tal guisa che in mill'anni trovar non posso un'ora.

Se alcun chiede il perché, rispondo solo d'ignorarlo e pur dentro il cor mi avvisa che vien dal veder voi, dolce Signora.

\section{AVERINI}

Del mio stato così mi sento incerto, che dentro ho il fuoco, e per il freddo tremo; rido senza ragione, e intanto gemo, m'appiglio a tutto, e mio niente ho di certo;

a ciò in cui credo, essere contro avverto fuoco dal cuore, e dagli occhi acqua spremo, provo speranza, e al tempo stesso temo, sono in discesa, e salgo un sentiero erto.

Stando a terra mi levo al ciel volando, mi par mill'anni un'ora, e all'improvviso di mille anni non riesco a fare un'ora.

Perché così mi vada comportando, non saprei dire, o meglio, son d'avviso ch'è in quanto v'ho veduto, mia signora. 
É evidente, em Peragallo, a alteração combinatória das rimas nas quadras, passando das rimas opostas para as alternadas, a fim de conservar em posição estratégica, no fim da primeira quadra, o verso mais bonito de toda a composição. Com mais umas ligeiras deslocações de palavras e a substituição da palavra "causa" pelo seu contrário, "fim", aqui temos os pequenos preços a pagar por duas quadras traduzidas brilhantemente, praticamente perfeitas. Igualmente bem se sai Averini, mas os seus versos 4 e 8 - fundamentais, porque fecham as respectivas quadras - não são tão bonitos como os de Camões que, por vezes, Peragallo consegue reproduzir até nas suas consonâncias e assonâncias (abarco/abbraccio). Cannizzaro, pelo contrário, não demonstra estar tão à vontade para solucionar os problemas métricos e linguísticos que o texto coloca. A sua primeira quadra é até confusa sintáctica e semanticamente, enquanto o verso 10 ecoa a pesada locução "di tal guisa”, já utilizada no verso 1 . Neste mesmo terceto, a versão de Peragallo apresenta uma espécie de hiper-tradução que desvia só num sentido um texto potencialmente mais vasto, acrescentando a palavra deleite ("diletto"). De facto, o terceto de Camões desenha uma situação de confusão espaço-temporal que, conforme se olhe do ponto de vista psicológico ou do ponto de vista estrutural, resulta ser ora o espelho dum complicado estado psíquico e intelectual, ora mais uma boa antítese para tecer a subtil trama retórica que rege todo o soneto. Mas com certeza não se prende apenas com a procura dum deleite ocasional, um "passatempo", como Peragallo deixa entender. Mesmo assim é uma atitude compreensível e coerente: o italiano "diletto", em lugar do português "de jeito", é ainda um bom exemplo de tradução que, sem prejudicar muito o conteúdo, o logos, o significado, aposta muito no significante, na conservação e transmissão dos fonemas. Aposta sempre arriscada e nem sempre indispensável, ao contrário do que talvez se pense quando se fala da tradução poética, mas que Peragallo, neste caso, ganha sem dúvida. 


\section{Conclusões}

Prospero Peragallo não prosseguiu o seu percurso de pioneiro porque lhe devem ter faltado um estímulo e uma editora maiores e, provavelmente, o seu trabalho não passou de um divertissement. Ainda que eruditas e de bom gosto, estas traduções, precedidas por publicações avulsas em revistas como Círculo Camoniano, nunca tiveram o alcance de um autêntico trabalho editorial como o Camões lírico bem requeria numa Itália que ainda o ignorava. Potencialmente, os tradutores não faltavam, mas o trabalho do tradutor, como o do poeta, mede-se também nas longas distâncias, na capacidade de construção de uma obra, não apenas na inspiração fugidia do momento. Por isso podemos apontar para os defeitos, sempre discutíveis, aliás, das traduções de Cannizzaro e Averini, mas temos de reconhecer que estes foram os únicos que, de facto, levaram a cabo trabalhos de fôlego com base não apenas na inspiração momentânea ou nas hipotéticas "afinidades electivas" entre eles e um ou outro soneto, mas planeando publicações orgânicas que dessem a conhecer ao leitor italiano uma faceta inteiramente desconhecida do poeta português. É evidente, pois, que traduzir alguns sonetos e traduzi-los todos, ou traduzir alguns juntamente com odes, elegias e canções, não é a mesma coisa. A obra de fôlego levanta problemas de coerência linguística, ou seja, lexical, sintáctica e estilística, a que o tradutor ocasional pode esquivar-se mais facilmente.

Quanto a isso, além de uma ou outra solução apreciável, o Camões (ou não seria mais justo dizer os Camões?) de Peragallo e de Cannizzaro acaba por parecer-nos um poeta italiano menor da segunda metade do século XIX, isto é, demasiado sujeito ao tempo e ao modo de entender a literatura dos seus tradutores. Que isto seja ou não inevitável, é matéria para a numerosa bibliografia teórica sobre arte e técnica da tradução, mas, de facto, enquanto o Camões histórico 
assimilou a língua de Petrarca tornando-a linfa para o seu português, com a liberdade com que também aqui, de passagem, se deu vagamente conta, esta mesma língua portuguesa traduzida entre finais do século XIX e princípio do século XX é já a língua do petrarquismo tardio, vício de origem de longos séculos de poesia italiana. É um petrarquismo pós-leopardiano, que de Leopardi só consegue extrair o apego aos aspectos linguísticos mais caducos da tradição. É também a língua conservadora dos libretos de ópera (ou de uma certa ideia da ópera veiculada por uma ou outra ária famosa), da musicalidade sem música, rebuscada até ao excesso, mas sempre em risco de cair na vacuidade, na imitação de imitações. O problema é antigo e coloca-se também em outras áreas linguísticas, visto que já Ezra Pound, em 1910, escrevia:

A beleza de Camões só será exactamente reproduzida em Inglês quando os tradutores deixarem de substituir as palavras portuguesas por palavras inglesas derivadas do mesmo étimo latino. [...] Uma tradução repleta de latinismos é como que uma imitação barata de Milton - e, se se deseja uma versão miltoniana $[\ldots]$ é preferível ir ao próprio Milton ${ }^{26}$.

Esse Camões lê-se às vezes com prazer, mas, quando o prazer acaba, vem socorrer-nos apenas o interesse arqueológico por um gosto literário peculiar que, todavia, já estava prestes a desaparecer; pois se o Camões de Peragallo chegou na véspera das pequenas/grandes revoluções na língua poética operadas por um poeta como Giovanni Pascoli ou pelo "Crepuscolarismo", que podemos dizer então do Camões de Cannizzaro, publicado em plena revolução de Novecentos (vale a pena lembrar que a Itália é o país onde o Futurismo nasceu)?

26 E. Pound, The Spirit of Romance, 1910 (cf. a publicação do capítulo avulso, trad. port. de Isabel Pedro dos Santos, posfácio de Stephen Wilson: E. Pound, Camões, Lisboa, Fenda, 2005, pp. 14-15). 
Por outro lado, com um à-vontade interpretativo talvez superior ao da sua própria tradução, justamente célebre, d'Os Lusíadas (sensação pessoal, não comprovada por nenhum estudo comparado que, até agora, se tenha realizado), Riccardo Averini aparece nesse contexto como uma espécie de primeiro e último tradutor italiano do Camões lírico. Uma versão que tem os seus pontos de força numa dicção eficaz e moderna dentro das formas poéticas clássicas, sempre respeitadas. Uma versão que, como em certas obras de restauro arquitectónico, sabe mostrar as camadas antigas por baixo da mais moderna, devolvendo à leitura, numa sensação única, o sentido do passado e do presente, do mutável e do imutável, de tudo o que, num clássico, achamos irremediavelmente alheio, longínquo e, ainda assim, tão nosso. 